\title{
Lipoprotein(a) accelerated the progression of atherosclerosis in patients with end- stage renal disease
}

Kun Ling Ma ${ }^{1 *}$, Tie Kai Gong ${ }^{1,2}$, Ze Bo Hu¹, Yang Zhang ${ }^{1}$, Gui Hua Wang ${ }^{1}$, Liang Liu', Pei Pei Chen', Jian Lu', Chen Chen Lu and Bi Cheng Liu'

\begin{abstract}
Background: Increased plasma level of lipoprotein(a) (Lpa) is a risk factor of cardiovascular diseases. This study aimed to explore the role of Lpa in the progression of atherosclerosis in patients with end-stage renal disease (ESRD) and to investigate whether its potential mechanism is mediated by CXC chemokine ligand 16 (CXCL16) and low-density lipoprotein receptor (LDLr).

Methods: This is a retrospective clinical study. From January 2015 to April 2016, forty-six ESRD patients from Danyang First People's Hospital were investigated. The patients were grouped according to their plasma Lpa levels: control group ( $L \mathrm{pa}<300 \mathrm{mg} / \mathrm{l}, n=23)$ and high $\mathrm{Lpa}$ group ( $\mathrm{Lpa} \geq 300 \mathrm{mg} / \mathrm{l}, n=23)$. ESRD Patients with acute infective diseases, cancer, and/or chronic active hepatitis were excluded. Biochemical indexes and lipid profiles of the patients were measured. Surgically removed tissues from the radial arteries of ESRD patients receiving arteriovenostomy were used for the preliminary evaluation of atherosclerosis. Haematoxylin-eosin (HE) and filipin staining were used to observe foam cell formation. Protein expression levels of Lpa, CXCL16, and LDLr were detected by immunohistochemistry staining and immunofluorescent staining.

Results: There was more foam cell formation and cholesterol accumulation in the radial arteries of the high Lpa group than in those of the control group. Furthermore, the expression levels of Lpa, CXCL16, and LDLr were significantly increased in the radial arteries of the high Lpa group. Correlation analyses showed that the protein expression levels of Lpa $(r=0.72, P<0.01)$, LDL $r(r=0.54, P<0.01)$, and CXCL16 $(r=0.6, P<0.01)$ in the radial arteries of ESRD patients were positively correlated with the plasma Lpa levels. Further analyses showed that the co-expression of Lpa with LDLr or CXCL16 was increased in the high Lpa group.

Conclusions: High plasma Lpa levels accelerated the progression of atherosclerosis in ESRD through inducing Lpa accumulation in the arteries, which was associated with LDLr and CXCL16. These two lipoproteins could both be major lipoprotein components that regulate the entry of Lpa into arterial cells.
\end{abstract}

Keywords: Lipoprotein (a), Atherosclerosis, LDLr, CXCL16, End-stage renal disease

\footnotetext{
* Correspondence: klma05@163.com

${ }^{1}$ Institute of Nephrology, Zhong Da Hospital, Medical School of Southeast

University, NO. 87, Ding Jia Qiao Road, Nang Jing City 210009, Jiang Su

Province, China

Full list of author information is available at the end of the article
}

(c) The Author(s). 2018 Open Access This article is distributed under the terms of the Creative Commons Attribution 4.0 International License (http://creativecommons.org/licenses/by/4.0/), which permits unrestricted use, distribution, and reproduction in any medium, provided you give appropriate credit to the original author(s) and the source, provide a link to the Creative Commons license, and indicate if changes were made. The Creative Commons Public Domain Dedication waiver (http://creativecommons.org/publicdomain/zero/1.0/) applies to the data made available in this article, unless otherwise stated. 


\section{Background}

Cardiovascular diseases (CVDs), which are mainly caused by atherosclerosis, are the leading cause of death in end-stage renal disease (ESRD) patients [1]. The incidence of atherosclerosis in ESRD patients is significantly higher than that in the general population [2]. It was found that genetically increased levels of lipoprotein(a) (Lpa) were associated with an increased risk of coronary disease [3]. In the Atherosclerosis Risk in Communities Study, Virani et al. illustrated that plasma Lpa levels were positively associated with CVD events [4]. Momiyama et al. demonstrated that plasma Lpa levels were positively correlated with atherosclerosis in the abdominal aorta and coronary artery [5]. However, the potential mechanisms underlying Lpa-induced atherosclerosis progression remain unclear.

Lpa contains two different polypeptides, one of which has been proven to correspond to the B-100 protein in LDL [6]. Romagnuolo et al. demonstrated that the low-density lipoprotein receptor (LDLr) mediated Lpa internalization in HepG2 cells by identifying the analogous structure of LDL [7]. Membrane-bound CXC chemokine ligand 16 (CXCL16) has been reported as a scavenger receptor that internalizes oxidized LDL [8] and might be involved in the progression of atherosclerosis [9].

Therefore, this study aimed to investigate the role of Lpa in the progression of atherosclerosis and to explore the association of Lpa deposition with LDLr and CXCL16 expression in radial arteries of ESRD patients.

\section{Methods}

\section{Study design}

This is a retrospective clinical study. From January 2015 to April 2016, forty-six ESRD patients from Danyang First People's Hospital were investigated. The patients were grouped according to their plasma Lpa levels: control group (Lpa $<300 \mathrm{mg} / \mathrm{l}, n=23$ ) and high Lpa group (Lpa $\geq 300 \mathrm{mg} / \mathrm{l}, n=23$ ). ESRD Patients with acute infective diseases, cancer, and/or chronic active hepatitis were excluded.

\section{Tissue specimens}

Excised radial artery tissues from ESRD patients were obtained during arteriovenous fistula surgery. After being washed with phosphate buffered saline (PBS), the tissues were immediately immersed in $4 \%$ paraformaldehyde for $24 \mathrm{~h}$. Then, the tissues were dehydrated and embedded in paraffin. Paraffin sections with a thickness of $4 \mu \mathrm{m}$ were used for subsequent experiments.

\section{Clinical biochemical assays}

Blood samples from ESRD patients were obtained for the clinical biochemical assays. The plasma levels of Lpa, total protein (TP), albumin (ALB), triglycerides (TGs), total cholesterol (TC), high-density lipoprotein (HDL), low-density lipoprotein (LDL), apolipoprotein A1 (Apo $\mathrm{A} 1)$, Apo $\mathrm{B}$, calcium (Ca), phosphate (P), and intact parathyroid hormone (iPTH) were detected by a Coulter AU580 automatic biochemical analyzer (Beckman, USA). Red blood cells (RBCs) and haemoglobin ( $\mathrm{Hb}$ ) levels were measured by an automated haematology analyzer (Sysmex, Japan). The plasma levels of C-reactive protein

Table 1 Basic clinical and biochemical data for the patients

\begin{tabular}{|c|c|c|}
\hline Parameters & Control $(n=23)$ & Lpa group $(n=23)$ \\
\hline \multicolumn{3}{|l|}{ Original disease distribution (n) } \\
\hline Chronic glomerulonephritis & 14 & 16 \\
\hline Diabetic nephropathy & 5 & 5 \\
\hline Nephrotic syndrome & 0 & 1 \\
\hline Obstructive nephropathy & 1 & 1 \\
\hline Hypertension & 1 & 0 \\
\hline Lupus nephropathy & 1 & 0 \\
\hline Polycystic kidney & 1 & 0 \\
\hline $\begin{array}{l}\text { Previous cardiovascular } \\
\text { disease/events(n) }\end{array}$ & $5 / 1$ & $5 / 3$ \\
\hline \multicolumn{3}{|l|}{$\operatorname{Sex}(n)$} \\
\hline Female & 11 & 7 \\
\hline Male & 12 & 16 \\
\hline Age(y) & $55.4 \pm 12.2$ & $51.7 \pm 13.4$ \\
\hline Weight(kg) & $61.0 \pm 12.1$ & $61.8 \pm 10.4$ \\
\hline $\mathrm{BMI}\left(\mathrm{kg} / \mathrm{m}^{2}\right)$ & $22.2 \pm 2.9$ & $22.2 \pm 2.3$ \\
\hline $\operatorname{Scr}(\mu \mathrm{mol} / \mathrm{L})$ & $665(543,823.2)$ & $858(694.2,1216.1)$ \\
\hline WC(cm) & $76.5 \pm 7.9$ & $78.5 \pm 7.6$ \\
\hline $\mathrm{CRP}(\mathrm{mg} / \mathrm{L})$ & $5.1(1.6,8.0)$ & $4.8(2.7,12.1)$ \\
\hline $\mathrm{ESR}(\mathrm{ml} / \mathrm{h})$ & $52.0 \pm 34.1$ & $67.6 \pm 32.9$ \\
\hline $\mathrm{Hb}(\mathrm{g} / \mathrm{L})$ & $76.3 \pm 15.6$ & $78.0 \pm 16.6$ \\
\hline $\mathrm{RBC}\left(\times 10^{12} / \mathrm{L}\right)$ & $2.66 \pm 0.54$ & $2.74 \pm 0.51$ \\
\hline $\mathrm{TP}(\mathrm{g} / \mathrm{L})$ & $62.6 \pm 8.2$ & $58.9 \pm 10.2$ \\
\hline $\mathrm{ALB}(\mathrm{g} / \mathrm{L})$ & $37.5 \pm 6.6$ & $31.8 \pm 7.2$ \\
\hline$A L T(U / L)$ & $14.73 \pm 7.19$ & $14.01 \pm 8.61$ \\
\hline AST(U/L) & $19.3 \pm 1.6$ & $19.15 \pm 1.35$ \\
\hline TG $(\mathrm{mmol} / \mathrm{L})$ & $1.61(0.86,2.69)$ & $1.21(0.90,1.59)$ \\
\hline $\mathrm{T}-\mathrm{CHO}(\mathrm{mmol} / \mathrm{L})$ & $3.90 \pm 0.65$ & $4.01 \pm 0.59$ \\
\hline LDL (mmol/L) & $1.94(1.85,2.08)$ & $2.16(1.9,2.36)$ \\
\hline $\mathrm{HDL}(\mathrm{mmol} / \mathrm{L})$ & $1.03(0.73,1.21)$ & $0.99(0.92,1.15)$ \\
\hline ApoA (mmol/L) & $1.13(0.97,1.2)$ & $1.14(1.01,1.35)$ \\
\hline ApoB (mmol/L) & $0.73 \pm 0.2$ & $0.83 \pm 0.22$ \\
\hline $\mathrm{Ca}(\mathrm{mmol} / \mathrm{L})$ & $2.13 \pm 0.25$ & $1.99 \pm 0.27$ \\
\hline $\mathrm{P}(\mathrm{mmol} / \mathrm{L})$ & $1.79 \pm 0.61$ & $1.93 \pm 0.56$ \\
\hline $\operatorname{CaxP}\left(\mathrm{mmol}^{2} / \mathrm{L}^{2}\right)$ & $47.79 \pm 15.74$ & $48.31 \pm 15.51$ \\
\hline iPTH (ng/L) & $301.2(148.1373 .4$ & $273.2(130.4553 .6)$ \\
\hline
\end{tabular}

There was no difference compared every index in the inflamed group with that in the control, $P>0.05$ 
(CRP) were detected by an automated protein analyzer (Siemens, Germany).

\section{HE staining}

The sections were dewaxed and hydrated. The sections were then stained with Harris haematoxylin solution for $15 \mathrm{~min}$ at room temperature. After differentiation with $1 \%$ acid alcohol for $1 \mathrm{~min}$, the sections were incubated with $1 \%$ eosin for $5 \mathrm{~min}$.

\section{Filipin staining}

The sections were dewaxed and hydrated. The sections were then incubated with a Filipin working solution $(50 \mu \mathrm{g} / \mathrm{ml})$ for $30 \mathrm{~min}$ at room temperature. The samples were observed by fluorescence microscopy. Five microscopic fields of each section $(n=5)$ were chosen randomly for fluorescence intensity evaluation by ImageJ software.

\section{Immunohistochemical staining}

After deparaffinization, the sections were immersed in $2 \%$ EDTA solution and heated to boiling for antigen retrieval; next, the sections were blocked with 3\% hydrogen peroxide for $10 \mathrm{~min}$ at room temperature. The slides were then incubated with primary antibodies for Lpa (Novus, USA), LDLr (Santa Cruz, USA) or CXCL16 (R\&D, USA) at $4{ }^{\circ} \mathrm{C}$ overnight. After reaction with biotin-labelled secondary antibodies, the sections were incubated with diaminobenzidine to detect the positive signal with a light microscopy. Five patients from each group were randomly selected for statistical analyses. Five random microscopic fields of each section $(n=5)$ were chosen for optical density quantitation by Image-Pro Plus software.

\section{Immunofluorescent staining}

After deparaffinization and antigen retrieval, the slides were treated with $0.25 \%$ Triton-100 for $15 \mathrm{~min}$ and blocked with $5 \%$ bull plasma albumin for $30 \mathrm{~min}$ at room temperature. Then, the sections were incubated with Lpa antibody at $4{ }^{\circ} \mathrm{C}$ overnight and reacted with the fluorescent secondary antibody for $2 \mathrm{~h}$ at room temperature. For double immunofluorescent staining, the sections were incubated with primary antibodies for

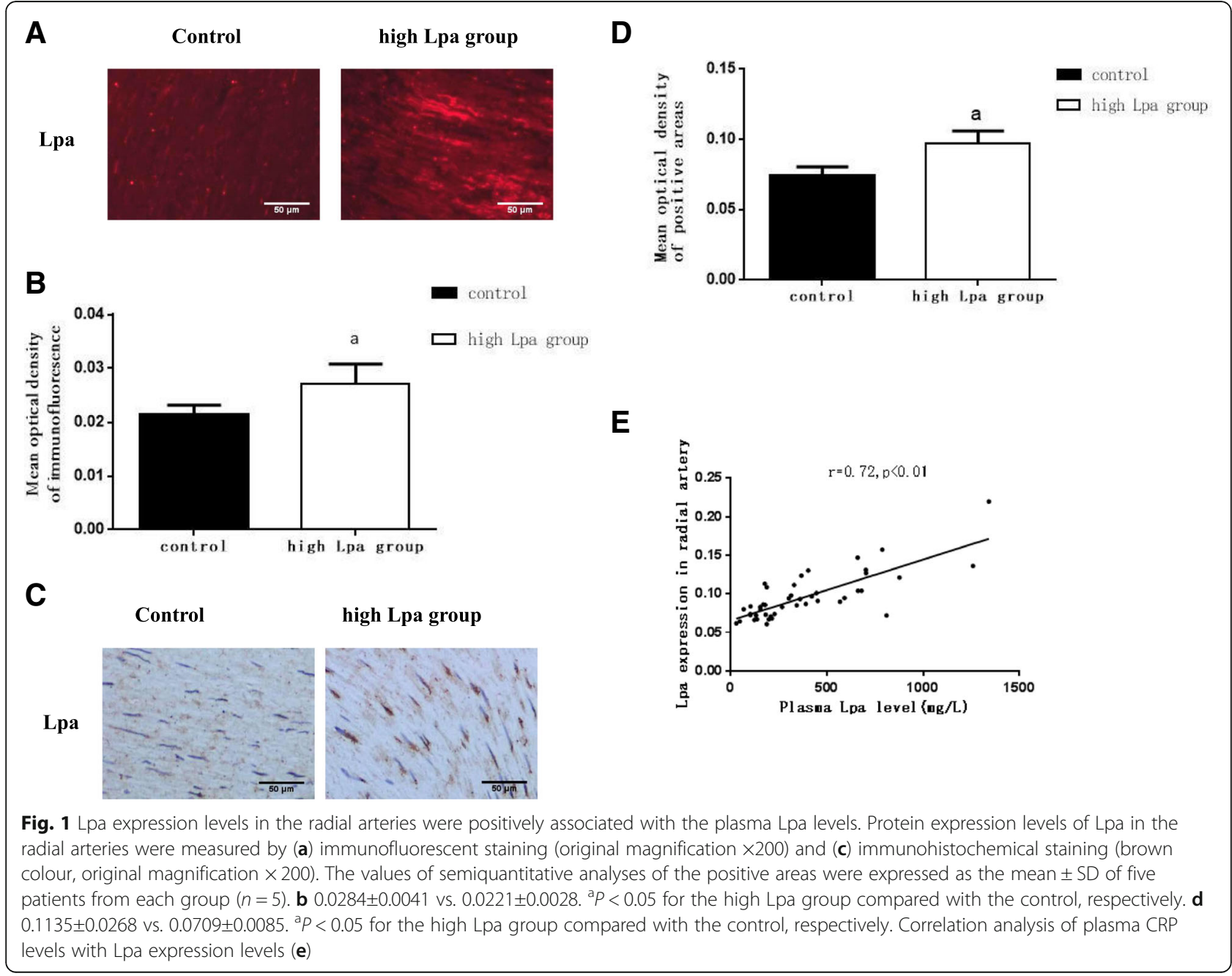


CXCL16, Lpa or LDLr at $4{ }^{\circ} \mathrm{C}$ overnight, followed by staining with secondary antibodies. All slides were observed with immunofluorescence laser scanning confocal microscopy. Five microscopic fields of each section $(n=5)$ were chosen randomly for fluorescence intensity evaluation by ImageJ software.

\section{Statistical analysis}

The sample size was based on available data. No statistical power calculation was conducted prior to the study. Data were analysed with SPSS 23.0. Normally distributed data are presented as the means $\pm \mathrm{SD}$, and independent-sample $t$ tests were used for comparisons between two groups. Abnormally distributed data are presented as the median (P25, P75), and Mann-Whitney U tests were used to compare the differences between two groups. Spearman's correlations and Pearson correlations were used for correlation analyses. Differences were considered statistically significant when $P<0.05$.

\section{Results}

Basic data for the patients in the two groups

As shown in Table 1, there were no significant differences in age, body weight, BMI, RBC, Hb, TP, ALB, GPT, GOT, TC, TG, LDL, HDL, ApoA1, ApoB, Ca, P, or iPTH levels $(P>0.05)$ between the high Lpa group and the control group (Table 1).

Lpa expression levels in radial arteries were positively associated with plasma Lpa levels

As shown in Fig. 1, the Lpa expression levels in the radial arteries of the high Lpa group were significantly increased when compared with those in the control group (Fig. 1a-d). Spearman correlation analysis showed that the Lpa expression levels in the radial arteries of the

\section{A}

Control

high Lpa group
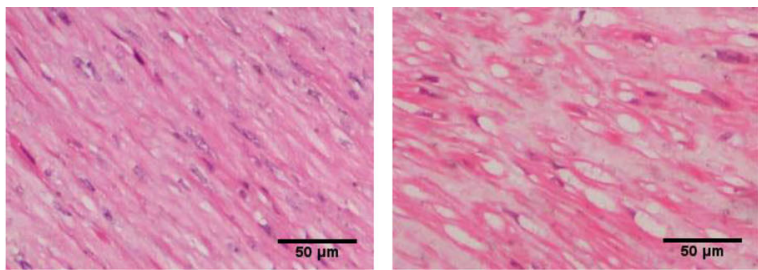

B

Control

high Lpa group
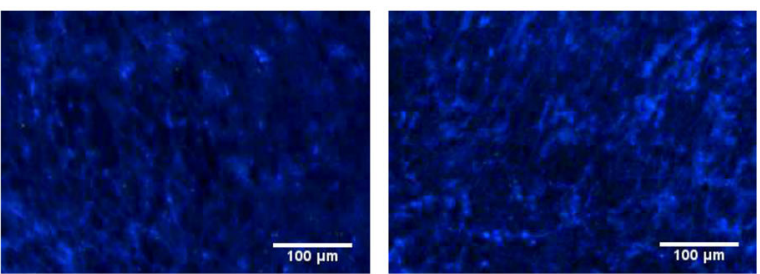

C

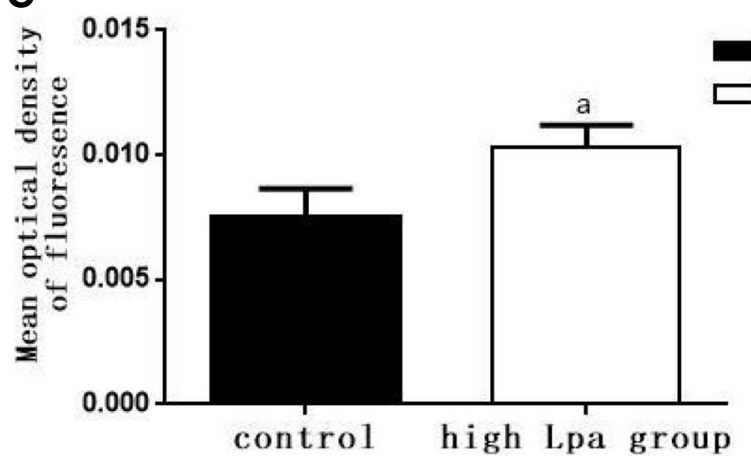

Fig. 2 Lpa accelerated foam cell formation and cholesterol deposition in the radial arteries of ESRD patients. The lipid accumulation in the radial arteries was determined by $(\mathbf{a})$ haematoxylin-eosin staining (original magnification $\times 400$ ) and (b) filipin staining (original magnification $\times 200$ ). The values of the semiquantitative analysis of the positive areas were expressed as the mean \pm SD of five patients from each group $(n=5)$. $\mathbf{c}$ $0.0101 \pm 0.0010$ vs. $0.0074 \pm 0.0012$. ${ }^{a} P<0.05$ for the high Lpa group compared with the control, respectively 
ESRD patients were positively correlated with the plasma Lpa levels (Fig. 1e).

\section{Lpa accelerated foam cell formation and cholesterol deposition in the radial arteries of ESRD patients}

To evaluate the effects of high levels of plasma LPa on the progression of atherosclerosis, we observed foam cell formation by HE staining and cholesterol accumulation by filipin staining. Foam cell formation in the radial arteries was significantly higher in the high Lpa group than in the control group (Fig. 2a). Filipin staining showed that cholesterol accumulation in the radial arteries of the high Lpa group also increased (Fig. 2b-c).

\section{Increased CXCL16 and LDLr expression levels in the high Lpa group}

By using immunohistochemical staining, we found that the protein expression levels of CXCL16 and LDLr in the radial arteries of the high Lpa group were significantly higher than in the control group (Fig. 3a-b).
Moreover, the expression levels of CXCL16 and LDLr in the radial arteries of the ESRD patients were positively correlated with their plasma Lpa levels (Fig. 3c-d).

\section{LDLr and CXCL16 modulated the transportation of plasma Lpa into the radial arteries}

Confocal microscopy observations showed that the co-expression of Lpa and LDLr was significantly increased in the high Lpa group, as well as the co-expression of Lpa and CXCL16 (Fig. 4a-d).

\section{Discussion}

Many studies have proposed increased plasma Lpa levels as an independent risk factor for cardiovascular disease $[10,11]$. Pedersen et al. found that increased Lpa expression levels accelerated uraemia-induced atherosclerosis, which might be mediated by the binding of oxidized phospholipids to Lpa [12]. Using a transgenic Watanabe heritable hyperlipidaemic rabbit model, Kitajima et al. reported that elevated plasma Lpa levels aggravated atherosclerosis

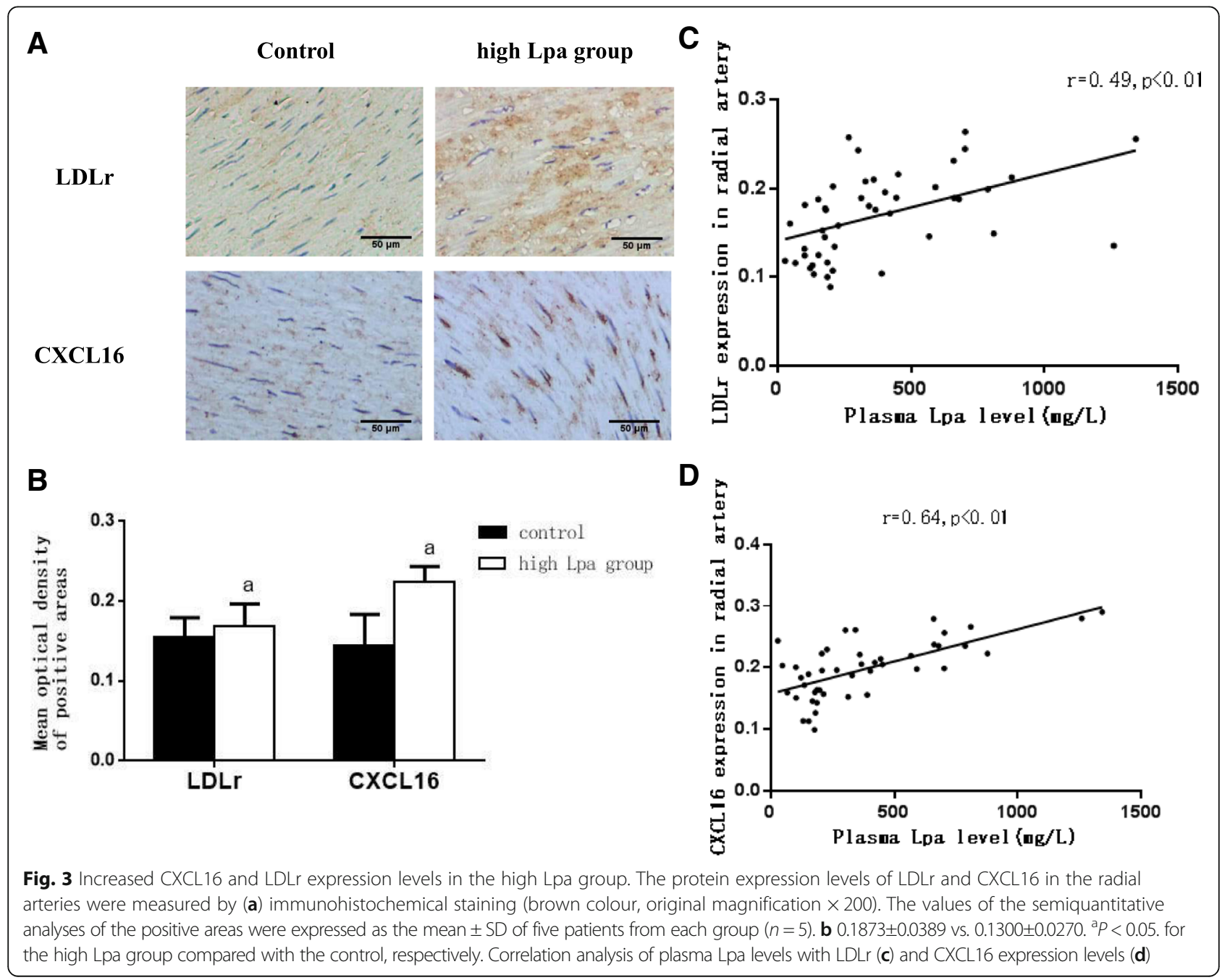


A
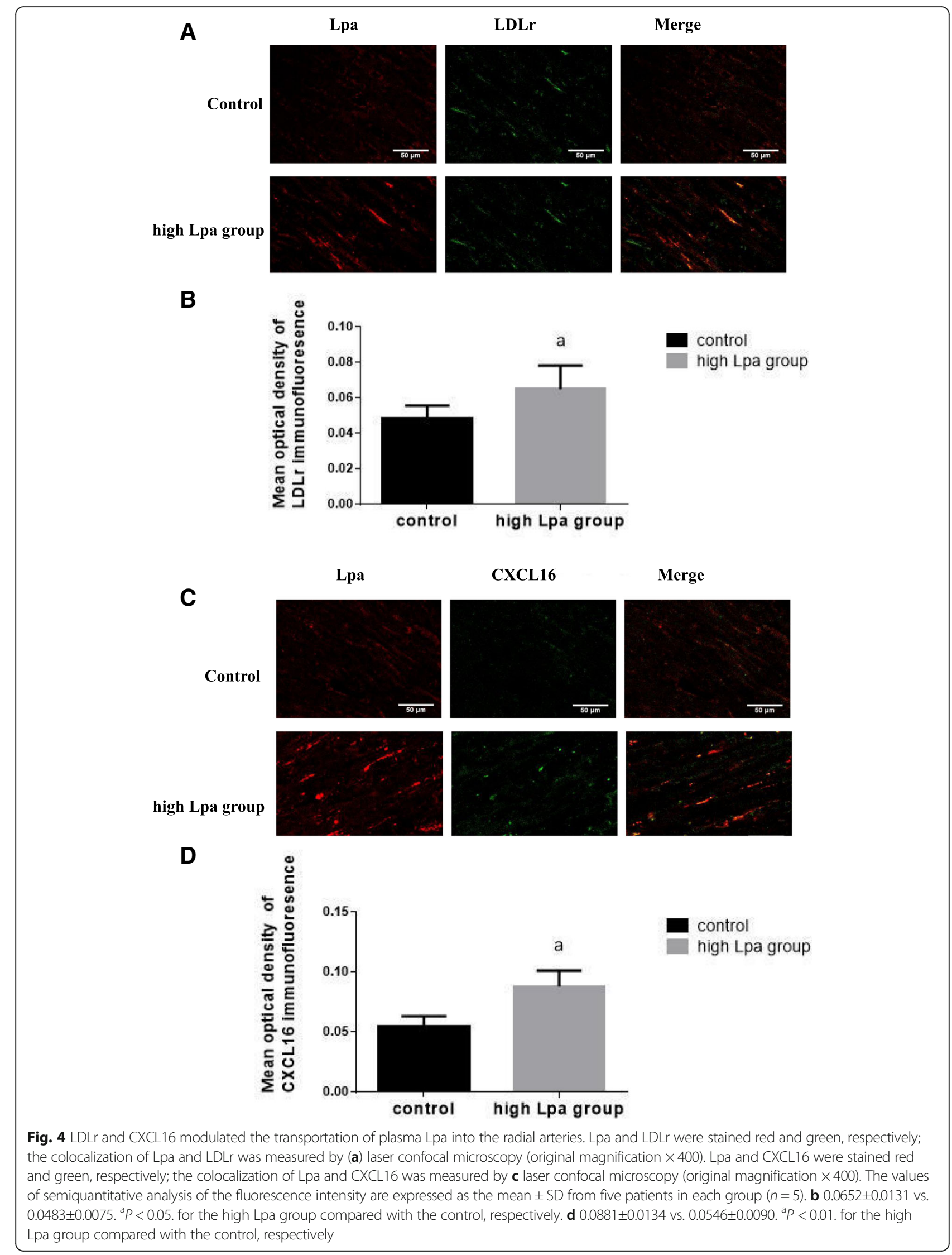

Merge 
in the coronary arteries and increased the incidence of myocardial infarction [13].

In this study, we observed that there was more Lpa deposition in the radial arteries of ESRD patients from the high Lpa group. Moreover, Filipin and HE staining showed that cholesterol accumulation and foam cell formation were significantly higher in the high Lpa group than in the control group. Our data suggest that high plasma Lpa levels might be the main cause of cholesterol accumulation and foam cell formation in the radial arteries of ESRD patients. As we know, hypercholesterolemia is a main risk factor for the progression of atherosclerosis. Lipoprotein (a), one of the components of plasma lipid profile, was shown similar effects with hypercholesterolemia on promoting systemic atherosclerosis. Therefore, high-Lpa induced radial atherosclerosis means that Lpa may contribute to the progression of cardiovascular disease in ESRD patients.

Clinical trials have demonstrated that proprotein convertase subtilisin/kexin type 9 inhibitors (PCSK9i) can significantly reduce LDL-cholesterol and Lpa levels [14]. Edmiston et al. found that the correlation between reduced LDL-cholesterol levels and Lpa levels in response to PCSK9i was moderate, and this result indicated that pathways beyond that of the LDLr were responsible for Lpa lowering [14]. Raal et al. reported that PCSK9 inhibitor-induced reductions in circulating Lpa levels partly depende on the LDLr-mediated uptake of Lpa [15]. The LDLr gene family member megalin/glycoprotein (gp) 330 was identified as the functional structure that binds to and mediates the cellular uptake of Lpa [16]. Yang et al. first reported that scavenger receptor class B type I bound to Lpa and facilitated Lpa-associated lipid uptake [17]. However, it is not clear whether CXCL16, which is also a scavenger receptor, can bind and internalize Lpa.

In this study, we found that LDLr and CXCL16 expression levels were increased in the high Lpa group, and the expression levels of these two proteins were positively correlated with the plasma Lpa levels. Confocal microscopy observations showed that Lpa colocalized with both LDLr and CXCL16 in the radial arteries of the ESRD patients. These data suggested that LDLr and CXCL16 might mediate the internalization of Lpa and thus contribute to lipid deposition in the radial arteries of ESRD patients.

\section{Limitations}

The small sample size and tiny tissues from radial arteries in two groups may limit acquiring more evidence to evaluate atherosclerosis caused by Lpa. This is also a key limitation for this pilot study. More samples will be collected in our future work to improve the statistical power. In addition, as each patient had different specific conditions (age, sex, complications, treatments, serum levels of phosphate, calcium, and intact parathyroid hormone, etc.), the data could be not well-controlled.

\section{Conclusions}

This study demonstrated that high plasma Lpa levels contributed to atherosclerosis in ESRD patients through increasing Lpa accumulation and foam cell formation in the radial arteries, and these actions were correlated with Lpa internalization mediated by LDLr and CXCL16.

\begin{abstract}
Abbreviations
ALB: Albumin; Apo A1: Apolipoprotein A1; Ca: Calcium; CRP: C-reactive protein; CVDs: Cardiovascular diseases; CXCL16: CXC chemokine ligand 16; ESRD: End-stage renal disease; Hb: Haemoglobin; HDL: High-density lipoprotein; iPTH: Intact parathyroid hormone; LDL: Low-density lipoprotein; LDLr: Low-density lipoprotein receptor; Lpa: Lipoprotein(a); P: Phosphate; PCSK9i: Proprotein convertase subtilisin/kexin type 9 inhibitors; RBCs: Red blood cells; TC: Total cholesterol; TGs: Triglycerides; TP: Total protein
\end{abstract}

\section{Acknowledgements}

The abstract of this study has been published in the form of meeting abstract in the journal of Nephrol Dial Transplant [18] authorized by the 54th ERA-EDTA congress convened in Madrid, Spain, 3rd-6th, 2017.

\section{Funding}

This work was funded by the National Natural Science Foundation of China (Grant 81,470,957), the Natural Science Foundation of Jiangsu Province (BK20141343), the Jiangsu Province Six Talent Peaks Project (2015-WSN-002), the Project for Jiangsu Provincial Medical Talent (ZDRCA2016077), the Fundamental Research Funds for the Central Universities (KYCX17-0169, KYZZ15-0061), the Jiangsu Province Ordinary University Graduate Research Innovation Project (SJZZ16-004), and the Clinical Medical Science Technology Special Project of Jiangsu Province (BL2014080). The funding bodies did not contribute to the design of study, collection, analysis, and interpretation of data, and in manuscript writing.

Availability of data and materials

All data generated or analysed during this study are included in this published article.

\section{Authors' contributions}

KLM designed the research; TKG, ZBH, YZ, GHW, LL, JL, PPC and CCL performed experiments, TKG and KLM analyzed the data and created the figures; KLM wrote the paper; $B C L$ provided valuable suggestions for the study design, data analysis, and paper writing. All authors read and approved the final manuscript.

\section{Ethics approval and consent to participate}

The study was approved by the Ethical Committee of Danyang People's Hospital, Jiangsu Province, and written informed consent was obtained from all subjects. The number of the ethics certificate is 2,015,008.

\section{Consent for publication}

Not applicable.

\section{Competing interests}

The authors declare that they have no competing interests.

\section{Publisher's Note}

Springer Nature remains neutral with regard to jurisdictional claims in published maps and institutional affiliations.

\section{Author details}

${ }^{1}$ Institute of Nephrology, Zhong Da Hospital, Medical School of Southeast University, NO. 87, Ding Jia Qiao Road, Nang Jing City 210009, Jiang Su Province, China. ${ }^{2}$ Renal Department, Danyang First People's Hospital, Jiang Su Province, China. 
Received: 6 November 2017 Accepted: 19 July 2018

\section{Published online: 02 August 2018}

\section{References}

1. Locatelli F, Pisoni RL, Combe C, Bommer J, Andreucci VE, Piera L, et al. Anaemia in haemodialysis patients of five European countries: association with morbidity and mortality in the Dialysis outcomes and practice patterns study (DOPPS). Nephrol Dial Transplant. 2004;19(1):121-32.

2. Drueke TB, Massy ZA. Atherosclerosis in CKD: differences from the general population. Nat Rev Nephrol. 2010;6(12):723-35.

3. Clarke R, Peden JF, Hopewell JC, Kyriakou T, Goel A, Heath SC, et al. Genetic variants associated with $\mathrm{Lp}(\mathrm{a})$ lipoprotein level and coronary disease. N Engl J Med. 2009;361(26):2518-28.

4. Virani SS, Brautbar A, Davis BC, Nambi V, Hoogeveen RC, Sharrett AR, et al. Associations between lipoprotein(a) levels and cardiovascular outcomes in black and white subjects: the atherosclerosis risk in communities (ARIC) study. Circulation. 2012;125(2):241-9.

5. Momiyama Y, Ohmori R, Fayad ZA, Tanaka N, Kato R, Taniguchi H, et al. Associations between serum lipoprotein(a) levels and the severity of coronary and aortic atherosclerosis. Atherosclerosis. 2012;222(1):241-4.

6. Utermann $G$, Weber $W$. Protein composition of $L p(a)$ lipoprotein from human plasma. FEBS Lett. 1983;154(2):357-61. Epub 1983/04/18. PubMed PMID: 6219896

7. Romagnuolo R, Scipione CA, Boffa MB, Marcovina SM, Seidah NG, Koschinsky ML. Lipoprotein(a) catabolism is regulated by proprotein convertase subtilisin/kexin type 9 through the low density lipoprotein receptor. J Biol Chem. 2015;290(18):11649-62.

8. Shimaoka T, Kume N, Minami M, Hayashida K, Kataoka H, Kita T, et al. Molecular cloning of a novel scavenger receptor for oxidized low density lipoprotein, SR-PSOX, on macrophages. J Biol Chem. 2000;275(52):40663-6.

9. Izquierdo MC, Martin-Cleary C, Fernandez-Fernandez B, Elewa U, SanchezNino MD, Carrero JJ, et al. CXCL16 in kidney and cardiovascular injury. Cytokine Growth Factor Rev. 2014;25(3):317-25.

10. Boffa MB, Koschinsky ML. Update on lipoprotein(a) as a cardiovascular risk factor and mediator. Curr Atheroscler Rep. 2013;15(10):360.

11. Kamstrup PR, Tybjaerg-Hansen A, Steffensen R, Nordestgaard BG. Genetically elevated lipoprotein(a) and increased risk of myocardial infarction. JAMA. 2009;301(22):2331-9. Epub 2009/06/11

12. Pedersen TX, McCormick SP, Tsimikas S, Bro S, Nielsen LB. Lipoprotein(a) accelerates atherosclerosis in uremic mice. J Lipid Res. 2010;51(10):2967-75.

13. Kitajima S, Jin Y, Koike T, Yu Y, Liu E, Shiomi M, et al. Lp(a) enhances coronary atherosclerosis in transgenic Watanabe heritable hyperlipidemic rabbits. Atherosclerosis. 2007;193(2):269-76.

14. Edmiston JB, Brooks N, Tavori H, Minnier J, Duell B, Purnell JQ, et al. Discordant response of low-density lipoprotein cholesterol and lipoprotein(a) levels to monoclonal antibodies targeting proprotein convertase subtilisin/kexin type 9. J Clin Lipidol. 2017;11(3):667-73.

15. Raal FJ, Giugliano RP, Sabatine MS, Koren MJ, Blom D, Seidah NG, et al. PCSK9 inhibition-mediated reduction in Lp(a) with evolocumab: an analysis of 10 clinical trials and the LDL receptor's role. J Lipid Res. 2016:57(6):1086-96.

16. Niemeier A, Willnow T, Dieplinger H, Jacobsen C, Meyer N, Hilpert J, et al. Identification of megalin/gp330 as a receptor for lipoprotein(a) in vitro. Arterioscler Thromb Vasc Biol. 1999;19(3):552-61.

17. Yang XP, Amar MJ, Vaisman B, Bocharov AV, Vishnyakova TG, Freeman LA, et al. Scavenger receptor-Bl is a receptor for lipoprotein(a). J Lipid Res. 2013; 54(9):2450-7.

18. Ma KL, Gong TK, Hu ZB, Zhang Y, Wang GH, Liu L, et al. Lipoprotein(a) acclerated the progression of atherosclerosis in patients with end-stage renal disease. Nephrol Dial Transplant. 2017;32(3):iii659-60.

Ready to submit your research? Choose BMC and benefit from:
- fast, convenient online submission
- thorough peer review by experienced researchers in your field
- rapid publication on acceptance
- support for research data, including large and complex data types
- gold Open Access which fosters wider collaboration and increased citations
- maximum visibility for your research: over 100M website views per year
At BMC, research is always in progress.
Learn more biomedcentral.com/submissions

